\title{
The Effects of Low Cost Airlines Growth in Italy
}

\author{
Domenico Campisi, Roberta Costa, Paolo Mancuso \\ Department of Business Engineering, University of Rome Tor Vergata, Via del Politecnico, Rome, Italy \\ E-mail: costa@disp.uniroma2.it \\ Received May 19, 2010; revised June 28, 2010; accepted July 5, 2010
}

\begin{abstract}
In recent years, low cost carriers (LCCs) have been the fastest growing sector of the aviation industry. The routes served by these carriers were undersized in comparison with principal routes, but deregulation made possible an efficient access to many new markets. The new generation of regional and low cost carriers have enabled a better matching of capacity to demand on routes previously served solely by large airlines, experiencing an increasing role in spatial development. Regional airports impact on local economies directly as a catalyst for other on-site economic activities and indirectly as a regional economic multiplier. This paper analyses the relation between LCC passenger traffic, secondary airports utilization and regional economic development. We underline that increased service at Italian secondary airports could affect economic development in the surrounding regions, including increased tourism and the potential for cluster development.
\end{abstract}

Keywords: Low Cost Airlines, Regional Economic Development, Secondary Airports

\section{Introduction}

In the present difficult situation for European aviation, one sector is performing relatively well, the so-called low cost carriers (LCCs). While flag-carriers are experiencing a severe crisis, withdrawing from routes and cutting staff, the low cost sector is expanding at a steady rate. There is concrete evidence that the LCCs could even become dominant players on a significant number of intra-European short-haul and point-to-point routes. For this reasons, the European industry and policy makers are questioning and investigating the extent to which the expansion of the LCCs will affect the traditional airline, characterized by hub-and-spoke networks. It is undeniable that airline deregulation has brought better service at lower prices to the majority of the population and that LCCs are the driving force behind the benefits of airline deregulation. It was frequently observed that when a new LCC enters a market, airfares drop [1].

In Europe, the experience of LCCs began in 1991 when the Irish carrier Ryanair transformed itself from a conventional regional airline into a carbon copy of the US low cost pioneer Southwest Airlines. At first, Ryanair focused on the large leisure market between Ireland and UK and in this phase the airline had a striking effect on services across the Irish Sea. After, Ryanair growth was the consequence of the strategic building of a network of intra-EU routes linking London's third airport,
Stansted, with over 50 under-utilized secondary airports located in a large number of countries. This strategy made Ryanair one of the largest LCC in Europe. The second case of success in the European LCCs was represented by EasyJet, established in 1995, after the acquisition of its rival Go, a British Airways offshoot. Several other LCCs have also been established as a reaction to these successful cases, including Buzz and Bmibaby in the UK, Virgin Express in Belgium, Transavia and Germanwings in Germany. LCCs have surely enabled a better matching of capacity to demand on routes previously served solely by large airline companies. Their appearance determined a rapid decreasing of airfares and determined the financial crisis of a large number of airline companies [2]. Moreover, these carriers have been experiencing an increasing role in spatial development [3]. Regional airports impact on local economies both directly as a catalyst for other on-site economic activities and indirectly as a regional economic multiplier [4]. This paper first look at the relation between LLC passenger traffic, secondary airports and regional economic development, then it underlines how the introduction of LCC service to previously under-served secondary airports affect the economic development in the surrounding Italian regions, including increased tourism and the potential for cluster development. In recent years, theoretical and empirical studies have identified significant changes in the distinctive characteristics of clusters and their evolutionary stages. The development of cluster competitive- 
ness is a function of different traits that from time to time have characterized their evolution [5]. We will try to identify in which cases the increased service at Italian secondary airports, that affected economic development in the surrounding regions, could possibly favourite a cluster development.

\section{The Market of Low Cost Carriers}

In order to analyze the LCC structure and strategy and to investigate the real profitability and sustainability of the LCC business model, we adopted the Structure-ConductPerformance (SCP) paradigm [6]. The SCP approach links elements of market structure to business conduct and performance in industrial economics. In this model, the market structure (Structure) is defined mainly by market concentration, number of firms and vertical integration. The behaviour of firms (Conduct), that could be collusive or competitive, depends strictly on pricing, cost structure of the firms, choice of technology, R \& D, advertising, entry barriers, etc. Performance is mainly defined by the extent of the firm's market power and it is measured by profitability, price level and efficiency.

The sample analyzed is formed by 15 LCCs (Table 1) and is representative of LCCs that serve routes to and from Italy. In our sample the competition is played between carriers in the European market, since they serve only intra-European routes on short and medium distances. The LCCs were chosen according to the STATFOR documents of Eurocontrol (European Organization for the Safety of Air Navigation) [7] and they represented in 2005 about the $70 \%$ of the European LCCs, corresponding to the $80 \%$ of the passenger traffic generated by LCCs in Italy.

Table 1. LCC passenger traffic in 2005 (to and from Italy).

\begin{tabular}{lcc}
\hline \multicolumn{1}{c}{ Low cost airlines } & \# passengers & market share s \\
\hline Itali Airlines & 113075 & $0.18 \%$ \\
SkyEurope & 171000 & $0.28 \%$ \\
Lauda Air & 386177 & $0.63 \%$ \\
Blue Air & 443500 & $0.72 \%$ \\
Bmibaby & 821000 & $1.34 \%$ \\
Eurofly & 1108291 & $1.81 \%$ \\
Volare Web & 1873429 & $3.05 \%$ \\
Hapag Lloyd & 1950000 & $3.18 \%$ \\
Germanwings & 2395000 & $3.90 \%$ \\
Sterling Airlines & 2455000 & $4.00 \%$ \\
Virgin Express & 2533000 & $4.13 \%$ \\
Flybe & 3386000 & $5.52 \%$ \\
Transavia & 4210000 & $6.86 \%$ \\
EasyJet & 18153000 & $29.58 \%$ \\
Ryanair & 21372000 & $34.82 \%$ \\
Total & 61370472 & $100 \%$ \\
\hline
\end{tabular}

Source: Eurocontrol, IATA, ICAO, LCC websites, 2006
As stated before, the Structure of a market is described by market concentration that is a function of the number of firms in a market and their respective market shares. We apply the Herfindahl-Hirschman Index (HHI) (1) to the LCC market shares (Table 1) in order to determine market concentration in the LCC market.

$$
H H I=\sum_{i} s_{i}^{2} \cong 0.22>\frac{1}{N}=\frac{1}{15}=0.07
$$

All the data analysed are from Eurocontrol, IATA (International Air Transport Association) and ICAO (International Civil Aviation Organization) and they refer to the year 2005 [7-9].

From the analysis of the sample, we observe an evident disparity in the dimension of the LCCs and the presence of a great concentration in the LCC market. In fact, the market is constituted by a small number of large companies (Ryanair, Easyget) with a combined market share exceeding $50 \%$ and a large number of small and medium companies characterized by a market share from $7 \%$ to less than $1 \%$.

Conduct represents the behaviour of firms in the market and it is highly influenced by the market demand. It is well-known that the market demand determines, in periods of economic uncertainty, the change of structure and intensity of competition in the airline sector. This is one of the many factors that caused the LCC success in the last decades. Under this aspect, we have to consider that the segmentation of the air travel demand, into business and leisure travellers, influences greatly airline pricing. Business travellers are less price sensitive, require more flexibility to change travel arrangements and are willing to pay much higher prices than leisure travellers. On the contrary, leisure travellers are usually considered to be price sensitive and, in their market segment, airlines can increase revenues by lowering prices [10]. As a consequence, many carriers have adopted a differential pricing: low-fares are targeted at leisure travellers to fill seats that would otherwise go empty. The pricing structure is preserved by applying constrains to low-fares making them unfeasible to business travellers (i.e. pre-booking periods) [11]. Concentrating their efforts on non-business travels LCCs have, in the last years, conquered a large part of the leisure market, especially on short routes.

From 1995 to 2006, LCCs registered a 45\% growth of the weekly seats (Figure 1) and more important is the constant increase of ASKs [12], that is the number of seats available for passengers multiplied by the number of kilometres those seats are flown. LCC share of the overall European ASKs has grown about 640\% since 1997 and LCCs are capturing a steadily growing share of the European market. It is important to point out that the growth of the LLC demand continued to go on after September 11 th, whereas full cost air companies faced severe crisis. Besides, many organization as IATA and ICAO consider a great part of LCC market to be a newly 
generated market.

As Conduct we intend also all the management peculiarity that are proper of LCCs. The business model of LCCs has a direct impact on their cost structure and consequently on the pricing strategies and revenues. In Table 2 are described the main aspects that distinguish low cost and full cost carriers, explaining the respective strategies of the two in their respect [13]. To achieve the low operating costs per passenger required, LCCs need to have as many seats on board of their aircraft as possible, to fill them as much as possible, and to fly the aircrafts as often as possible. The cost structure is classified in: not operating and operating costs. The first ones are not strictly connected with the LCC activity, while the second ones depend directly on it. In order to analyze the cost structure is obviously necessary to focus on the operating costs that reflect the more efficient management of LCC operations. Operating costs are divided in direct and indirect operating costs. Direct operating costs are: maintenance, passenger service costs, fuel and oil, navigation and airport fees, handling etc. Indirect operating costs are: marketing costs, staff costs, depreciation and interests, etc. Great influence on the direct operating costs has fuel and oil costs, but these are mostly independent from the efficiency of the carrier. The main cost difference between full cost and low cost carriers is represented by labour cost (about 30\%-35\%) and depends on three drivers: a greater productivity of the working-force, a difference in salary between low and full cost carriers, and a no-service model that allows the reduction of fly attendant and check-in staff.

The second cost difference in order of importance is on "sales and reservations" (about 13\%-18\%) and it is obtained by selling directly to customers via Internet and call centres and by using electronic ticketing. In this way, LCCs avoid travel agency commissions and computer reservation system fees. In the USA, Southwest registered in these cost areas an advantage of $50 \%$ over the main traditional carriers in 2003. It is interesting to notice that in the revolution of the distribution channels, the traditional carriers acted as followers instead than as incumbents, whilst LCCs, the new entrants, behaved as leaders. The third aspect that distinguishes LCCs is maintenance costs (a difference of about 12\%-17\% with full cost carriers): the competitive advantage, in this case, is caused by the homogeneity of the LCC fleet (a single aircraft model), an aggressive negotiation in maintenance contracts agreements and outsourcing. Other important differences in the cost structure of low cost and full cost carriers are ground landing and landing fees, for a total of $20 \%-25 \%$, both deriving from the strategic chose of LCCs of secondary airport, where better condition are negotiable. The remaining $10 \%-20 \%$ of cost divergence is due to other cost savings such as the no-service policy of LCCs, that is perhaps the area of cost savings most apparent to passengers [14]. A greater aircraft productivity is undoubtedly the primary source of LCC competitive advantage: it is obtained using non-congested secondary airports and not offering anything other than point-to-point services (i.e. like interlining). In fact, secondary airports charge airlines less than primary airports for using their services. Moreover, secondary airports are less busy, allowing less delays due to congestion. As said before, personnel productivity is another key area where LCCs gain competitive advantage: LCCs use a single aircraft model and, as a consequence, pilots and cabin crew can operate on any aircraft in the fleet. Another interesting factor to examine is the cost difference between low cost and full cost carriers

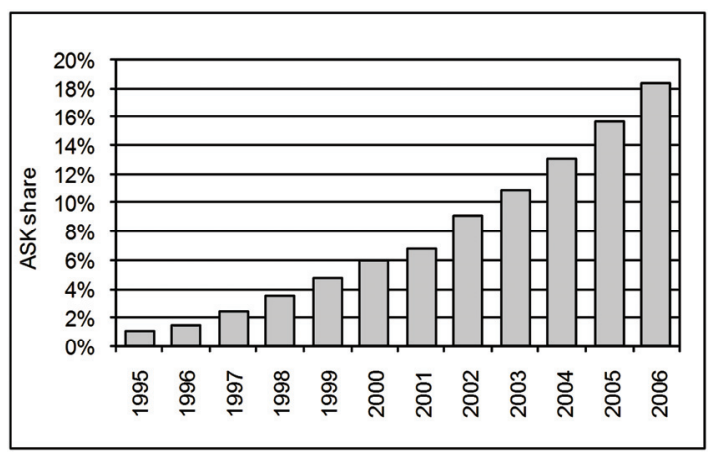

Figure 1. LCC ASK share (with respect to all the market).

Table 2. The business model of low cost and full cost carrier.

\begin{tabular}{|c|c|c|}
\hline & Low Cost Carriers & Full Cost Carriers \\
\hline Brand & One (low-fare) brand & $\begin{array}{l}\text { Extensions: } \\
\text { fare+service }\end{array}$ \\
\hline Fares & $\begin{array}{l}\text { Simplified fare } \\
\text { structure }\end{array}$ & $\begin{array}{l}\text { Complex fare } \\
\text { structure }\end{array}$ \\
\hline Distribution & $\begin{array}{l}\text { Online and call } \\
\text { centres }\end{array}$ & $\begin{array}{l}\text { Online, direct, travel } \\
\text { agent }\end{array}$ \\
\hline Airports & Secondary (mostly) & Primary \\
\hline Connections & Point-to-point & $\begin{array}{l}\text { Interlining, hub and } \\
\text { spokes }\end{array}$ \\
\hline Class segmentation & $\begin{array}{l}\text { One class } \\
\text { (high density) }\end{array}$ & Two class \\
\hline Aircraft utilisation & Very high & Medium to high \\
\hline Turnaround time & 25 min turnarounds & Low turnaround \\
\hline Product & One product: low fare & $\begin{array}{l}\text { Multiple integrated } \\
\text { products }\end{array}$ \\
\hline Aircraft & $\begin{array}{l}\text { Single type: } \\
\text { commonality }\end{array}$ & $\begin{array}{l}\text { Multiple types: } \\
\text { Scheduling } \\
\text { complexities }\end{array}$ \\
\hline Seating & $\begin{array}{l}\text { Small pitch, } \\
\text { no assignment }\end{array}$ & $\begin{array}{l}\text { Generous pitch, offers } \\
\text { seat assignment }\end{array}$ \\
\hline Customer service & $\begin{array}{l}\text { Generally under } \\
\text { performs }\end{array}$ & Full service, reliability \\
\hline $\begin{array}{l}\text { Operational } \\
\text { activities }\end{array}$ & Focus on core (flying) & $\begin{array}{l}\text { Extensions: e.g., } \\
\text { maintenance, cargo }\end{array}$ \\
\hline
\end{tabular}

Source: O'Connell and Williams, 2005 
with respect to the cost per ASK. In Figure 2 is clearly depicted as this difference decreases with the length of the flight (sector length). The reducing cost advantage, occurring with the increasing sector length, is due mainly to a decreasing acceptance of lack of service by passengers and an increasing revenue need in LCCs. Focusing on a sector length of $1,500 \mathrm{Km}$, the ICAO estimated the LCC cost advantage as: $30 \%$ on total crew costs, $5 \%$ on landing and handling charges, $50 \%$ on passenger related costs, $70 \%$ on sales costs and $60 \%$ for other costs [14].

To measure Performance is to measure the results of a firm in terms of productivity and profitability. Since the LCC model derives competitive advantage from a greater aircraft productivity and a more efficient cost structure, the performance of LCCs in 2005 is analysed by means of profitability and efficiency indexes. We choose three profitability indexes: ROI (Return on Investment), ROS (Return on Sales), ROE (Return on Equity). While we consider the Load Factor of LCCs as the efficiency index. The analysis evidences the existence of a small number of large LCCs that gained a high profitability, while a great number of medium and small carriers faced economic and financial difficulties (Table 3). The bad performance of smaller LCCs is motivated by an inefficient management of their operating costs, that is a dangerous deficiency while adopting the LCC business model. Volare Web performed the worst ROS, because the operative costs are one and half greater than the revenues of this LCC. This result reflects the financial problem faced by Volare Web that conducted the company to a controlled administration in order to avoid bankrupt, followed by its acquisition by the Alitalia Group. Figure 3 depicts the average value of each profitability index for: 1) large airline companies (more than 3 millions passenger traffic), and 2) small and medium airline companies (less than 3 millions passenger traffic). Volare Web was not considered because of the severe financial crisis. There is an evident gap between the two groups in all the profitability indexes, more so for the ROS index: that confirms the difficulty of smaller and medium LCCs to manage operating costs in accord to the LCC business model. The last performance index is a very important one in the LCC philosophy. The Load Factor is the percentage of seats filled with passengers: it indicates that an airplane is more efficiently utilized, lowering the operating costs and, as a result, the airfares. A good Load Factor assures the necessary utilization and productivity of critical LCC resources: personnel and aircrafts.

Figure 4 represents the Load Factors of the sample in 2005: the average value of this index is $75 \%$. An half of the sample has a Load Factor better than the average value and from Figure $\mathbf{5}$ it is evident that there is a correlation between a good financial performance (ROS) and a high Load Factor: only those carriers that are operatively efficient have financial success in the long run.

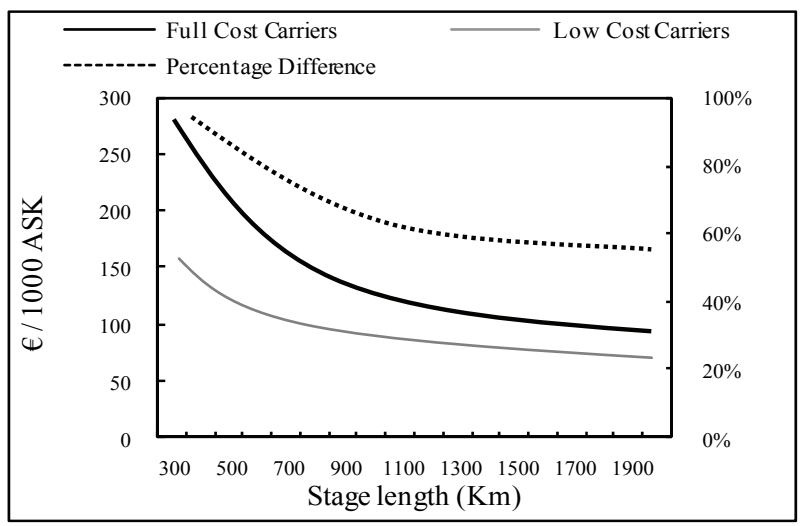

Figure 2. Cost per ASK in 2005.

Table 3. Low cost airlines: ROI, ROS, ROE (2005).

\begin{tabular}{lccc}
\hline \multicolumn{1}{c}{ Low cost carriers } & ROI & ROE & ROS \\
\hline Blue Air & $3.47 \%$ & $0.00 \%$ & $1.48 \%$ \\
Bmibaby & $-1.64 \%$ & $-10.00 \%$ & $-1.05 \%$ \\
EasyJet & $3.74 \%$ & $4.43 \%$ & $4.37 \%$ \\
Eurofly & $-4.65 \%$ & $-10.27 \%$ & $-6.59 \%$ \\
Flybe & $1.04 \%$ & $3.14 \%$ & $-5.28 \%$ \\
Germanwings & $5.72 \%$ & $18.51 \%$ & $2.38 \%$ \\
Hapag Lloyd & $9.09 \%$ & $0.00 \%$ & $3.61 \%$ \\
Itali Airlines & $-0.47 \%$ & $0.59 \%$ & $-0.94 \%$ \\
Lauda Air & $3.75 \%$ & $5.16 \%$ & $4.57 \%$ \\
Ryanair & $10.68 \%$ & $19.28 \%$ & $31.28 \%$ \\
SkyEurope & $-0.52 \%$ & $-7.46 \%$ & $-1.03 \%$ \\
Sterling Airlines & $-7.27 \%$ & $-3.45 \%$ & $-10.99 \%$ \\
Transavia & $3.20 \%$ & $7.38 \%$ & $4.10 \%$ \\
Virgin Express & $-8.98 \%$ & n.d. & $-7.73 \%$ \\
Volare Web & $-4.50 \%$ & $-37.02 \%$ & $-66.81 \%$ \\
\hline
\end{tabular}
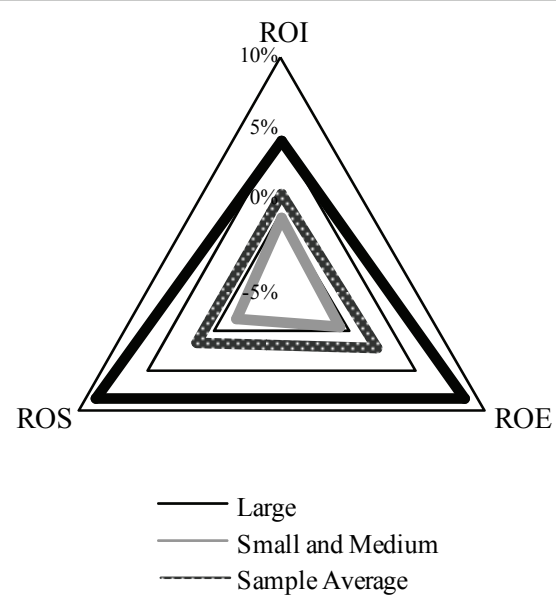

Figure 3. Average ROI, ROS, ROE for large, medium and small LCCs (2005). 


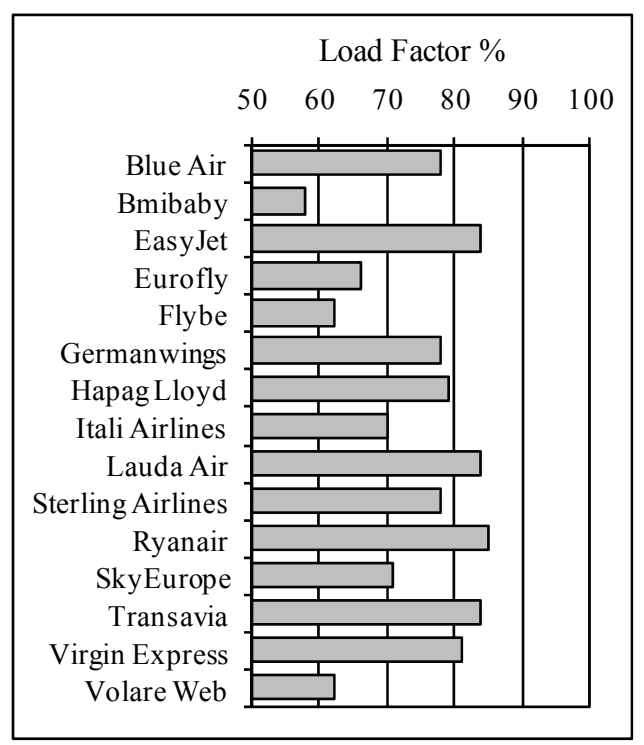

Figure 4. LCC Load Factors (2005).

Positions of Ryanair and Volare Web are not a surprise as the first is a best practice of LCCs and the second had very serous financial problems.

\section{Low Cost Carriers, Regional Airports and Geographic Clusters}

Aviation policy makers are facing several issues connected with the growth of LCCs. Among them there is the necessity to mitigate the environmental effects of this expansion, especially at secondary airports, since a great part of LCCs tend to select routes between regional airports. As a consequence, these airports are confronted with a rapidly increasing traffic, that requires large capital expenditure for infrastructure investments. The positive aspect of decentralization from main routes is economic regional development. Regional and secondary airports impact on local economies directly as a catalyst for other on-site economic activities and indirectly as a regional economic multiplier. Moreover, congestion at the major hubs can be lessened by developing secondary hubs: alternative airports around the main urban environment. These are typically remote from the city centre, with plentiful capacity but little traditional scheduled air service. Advantages in terms of lack of congestion, and consequently of pollution, are set against disadvantages in terms of surface access. In Italian airports this phenomenon is clearly observable from Table 4: data on passenger traffic are reported for each Italian airport and it is clearly visible the rapid traffic growth of smaller and regional airports with respect to principal ones [15].

The consistent increase in passenger traffic in regional airports is due mainly to the diffusion and success of LCCs that, in choosing secondary airports as their bases, determined the economic and traffic growth of regional airports.

In order to analyse this phenomenon in the Italian scenario, we considered only those regional and secondary airports that are utilized by the LCCs of the sample and the number of routes they operate on (Table 5).

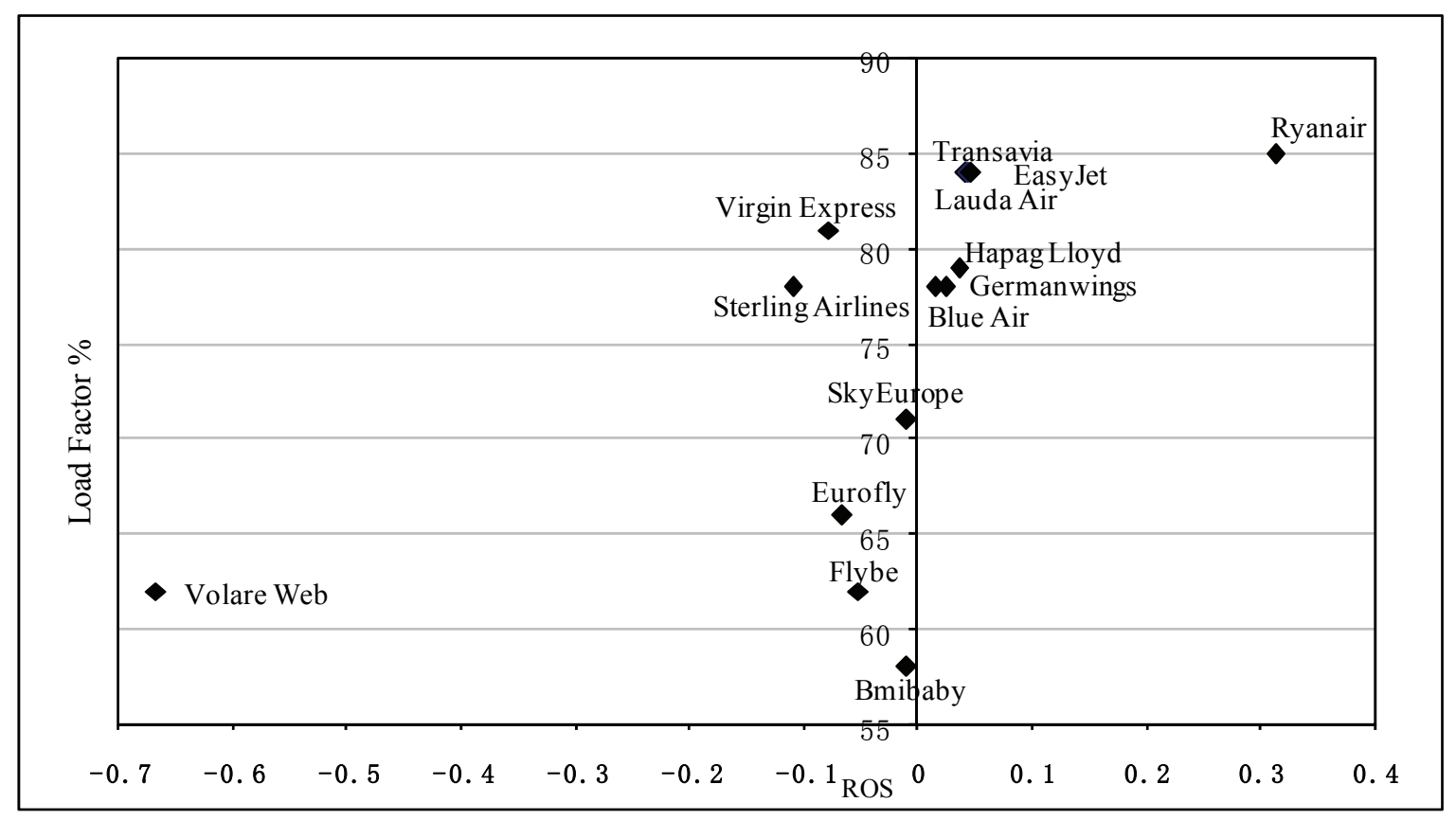

Figure 5. LCC Load Factors and ROS (2005). 
Some LCCs are not present in Table 5 (i.e. EasyJet) because they operate in primary airports.

The more promising type of regional economic development that could directly benefit from increasing passenger throughput at secondary airports is "cluster development". While the idea of the "cluster", first put forward by Michael Porter, has attracted some criticism, it is worth considering whether geographic proximity to a rapidly-growing airport could enhance the growth and knowledge spillovers of local industries [4]. Following this lead, we analyse traffic growth and accessibility (Table 6) of secondary airports served by the sample of LCCs under study.

Table 4. Italian airports: passenger traffic growth.

\begin{tabular}{|c|c|c|c|}
\hline Airports & $\begin{array}{c}\text { Passengers } \\
2000\end{array}$ & $\begin{array}{c}\text { Passengers } \\
2006\end{array}$ & $\begin{array}{c}\text { Increase } \\
\text { from } 2000 \\
\text { to } 2006\end{array}$ \\
\hline Alghero & 664330 & 1079843 & $62.55 \%$ \\
\hline Ancona & 433729 & 485929 & $12.04 \%$ \\
\hline Bari & 1251682 & 1659323 & $32.57 \%$ \\
\hline Bergamo & 1241138 & 4356143 & $250.98 \%$ \\
\hline Bologna & 3524789 & 3690953 & $4.71 \%$ \\
\hline Bolzano & 50124 & 68103 & $35.87 \%$ \\
\hline Brescia & 164804 & 409940 & $148.74 \%$ \\
\hline Brindisi & 614140 & 794378 & $29.35 \%$ \\
\hline Cagliari & 2067116 & 2355796 & $13.97 \%$ \\
\hline Catania & 3970754 & 5192697 & $30.77 \%$ \\
\hline Crotone & 53275 & 85221 & $59.96 \%$ \\
\hline Cuneo & 16492 & 18942 & $14.86 \%$ \\
\hline Firenze & 1521272 & 1703303 & $11.97 \%$ \\
\hline Foggia & 30297 & 7709 & $-74.56 \%$ \\
\hline Forlì & 45933 & 565341 & $1130.79 \%$ \\
\hline Genova & 1063146 & 1013288 & $-4.69 \%$ \\
\hline Lamezia Terme & 785060 & 1163121 & $48.16 \%$ \\
\hline Milano LIN & 6026342 & 9088607 & $50.81 \%$ \\
\hline Milano MXP & 20716815 & 19630514 & $-5.24 \%$ \\
\hline Napoli & 4136508 & 4588695 & $10.93 \%$ \\
\hline Olbia & 1336618 & 1671218 & $25.03 \%$ \\
\hline Palermo & 3231267 & 3831876 & $18.59 \%$ \\
\hline Parma & 75112 & 61429 & $-18.22 \%$ \\
\hline Perugia & 52802 & 54815 & $3.81 \%$ \\
\hline Pescara & 114024 & 350477 & $207.37 \%$ \\
\hline Pisa & 1246807 & 2334843 & $87.27 \%$ \\
\hline Reggio Calabria & 538048 & 398089 & $-26.01 \%$ \\
\hline Rimini & 251139 & 283492 & $12.88 \%$ \\
\hline Roma CIA & 829511 & 4234999 & $410.54 \%$ \\
\hline Roma FCO & 26288181 & 28683456 & $9.11 \%$ \\
\hline Torino & 2814850 & 3148807 & $11.86 \%$ \\
\hline Treviso & 281442 & 1300298 & $362.01 \%$ \\
\hline Trieste & 574665 & 615759 & $7.15 \%$ \\
\hline Venezia & 4135608 & 5825499 & $40.86 \%$ \\
\hline Verona & 2293799 & 2649655 & $15.51 \%$ \\
\hline
\end{tabular}

Source:Assaeroporti, 2000-2006
Table 5. Secondary Italian airports (2006).

\begin{tabular}{clc}
\hline $\begin{array}{c}\text { Secondary } \\
\text { Airport }\end{array}$ & LCCs using the airport as base & $\begin{array}{c}\text { Number of } \\
\text { routes }\end{array}$ \\
\hline Alghero & Ryanair, Germanwing & 8 \\
Bergamo & $\begin{array}{l}\text { Ryanair, Transavia, Blue Air, } \\
\text { Skyeurope Eurofly }\end{array}$ & 40 \\
Brescia & Eurofly & 1 \\
Brindisi & Volare Web & 1 \\
Ciampino & $\begin{array}{l}\text { Ryanair, Hapag Lloyd, Sterling } \\
\text { Airlines }\end{array}$ & 27 \\
Forlì & $\begin{array}{l}\text { Ryanair } \\
\text { Lamezia }\end{array}$ & $\begin{array}{l}\text { Ryanair, Hapag Lloyd, German- } \\
\text { wing, Volare Web }\end{array}$ \\
Olbia & Hapag Lloyd, Itali & 5 \\
Pisa & $\begin{array}{l}\text { Ryanair, Easyjet, Transavia, Hapag } \\
\text { Lloyd, Eurofly }\end{array}$ & 35 \\
Rimini & Hapag Lloyd, Eurofly \\
Treviso & Ryanair, Transavia, Skyeurope & 13 \\
Verona & Germanwing, Blue Air, Eurofly & 8 \\
\hline
\end{tabular}

Table 6. Secondary Italian airports: accessibility (2006).

\begin{tabular}{|c|c|c|c|c|c|}
\hline \multirow{2}{*}{$\begin{array}{c}\text { Secondary } \\
\text { Airport }\end{array}$} & \multirow{2}{*}{$\begin{array}{c}\text { Primary } \\
\text { airport }\end{array}$} & \multirow{2}{*}{$\begin{array}{l}\text { Accessibility } \\
\quad \text { (min) }\end{array}$} & \multicolumn{3}{|c|}{$\begin{array}{l}\text { Traffic increase from } \\
2000 \text { to } 2006\end{array}$} \\
\hline & & & Airplanes & Passengers & Cargo \\
\hline Alghero & Cagliari & 196 & $12 \%$ & $63 \%$ & $-65 \%$ \\
\hline Bergamo & $\begin{array}{l}\text { Milan } \\
\text { LIN-MXP }\end{array}$ & 7 & $26 \%$ & $251 \%$ & $36 \%$ \\
\hline Brescia & $\begin{array}{c}\text { Milan } \\
\text { LIN-MXP }\end{array}$ & 41 & $138 \%$ & $149 \%$ & $2084 \%$ \\
\hline Brindisi & Bari & 109 & $1 \%$ & $29 \%$ & $134 \%$ \\
\hline Rome CIA & Rome FCO & 0 & $106 \%$ & $411 \%$ & $37 \%$ \\
\hline Forlì & Bologna & 40 & $262 \%$ & $1131 \%$ & $-81 \%$ \\
\hline Lamezia & $\begin{array}{l}\text { Reggio } \\
\text { Calabria }\end{array}$ & 98 & $57 \%$ & $48 \%$ & $-17 \%$ \\
\hline Olbia & Cagliari & 225 & $33 \%$ & $25 \%$ & $-58 \%$ \\
\hline Pisa & Florence & 49 & $36 \%$ & $87 \%$ & $20 \%$ \\
\hline Rimini & Bologna & 61 & $29 \%$ & $13 \%$ & $-47 \%$ \\
\hline Treviso & Venice & 20 & $92 \%$ & $362 \%$ & $97 \%$ \\
\hline Verona & Venice & 63 & $6 \%$ & $16 \%$ & $20 \%$ \\
\hline
\end{tabular}

Observing Figure 6 it seems clear that LCCs success has a great deal to do with regional and secondary airports development. These airports gradually specialised in passengers transportation, leaving behind cargo transport (with the exception of Brescia, Brindisi and Treviso), according with the new alliances with LCCs. 


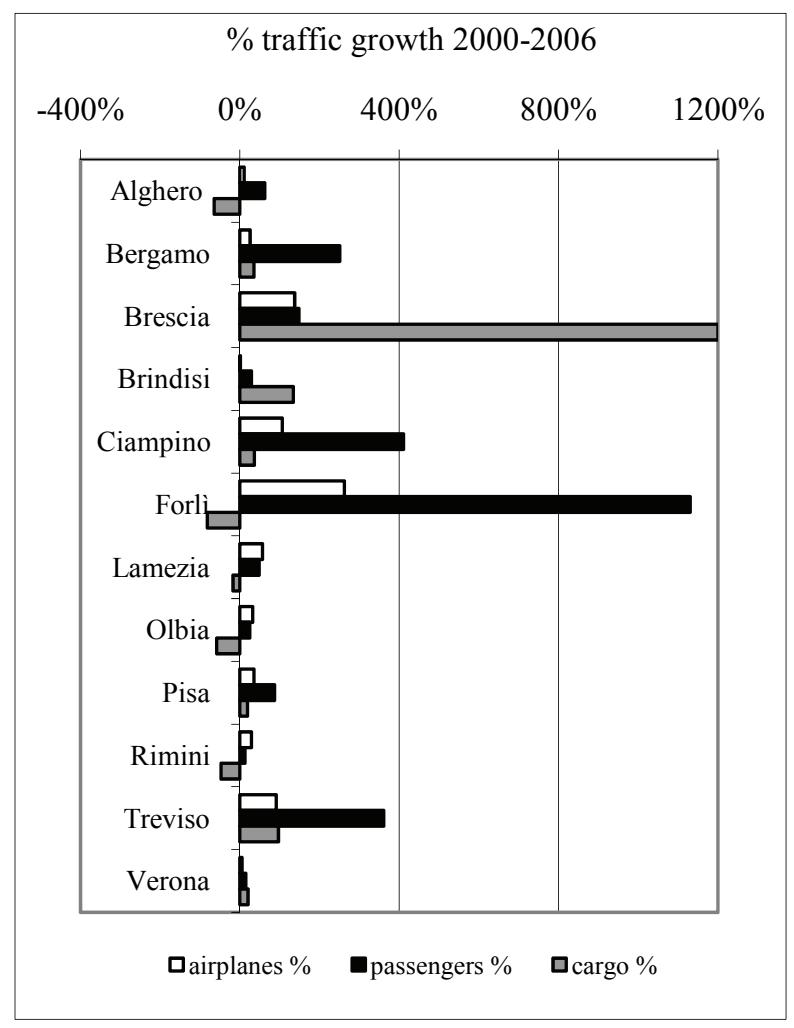

Figure 6. Secondary Italian airports: passenger and cargo traffic growth (2000-2006).

In order to realise different patterns in the development of secondary airports, is better, then, to focus only on passenger and airplane traffic (as airplane traffic we intend the number of airplanes that landed and departed from the airport). The airports of Treviso (secondary airport of Venice), Ciampino (secondary airport of Rome), Bergamo (secondary airports of Milan) and Forlì (secon- dary airport of Bologna) are the fastest growing in terms of passenger traffic, as result of being a secondary airport of big hubs such as Rome, Milan and secondarily Venice and Bologna.

In order to analyse the importance of geographical accessibility for cluster development (indicated by the traffic increase), we calculate "accessibility" for each secondary airport as the travel time in minutes between the primary and secondary airport (Table 6), as follows:

$$
T=\max \{0 ; t(C, S)-t(C, P)\}
$$

where $t(C, P)$ is the travel time (by car) to the primary airport of a city from the centre of the city and $t(C, S)$ is the travel time to the secondary airport from the same starting point. Travel time was calculated by means of the well known Michelin's website.

For example, for the airport of Treviso, the accessibility results 20 minutes, where applying (2):

$\mathrm{t}(\mathrm{C}, \mathrm{P})=\mathrm{t}$ (Venice Centre, Venice airport $)=54 \mathrm{~min}$, $\mathrm{t}(\mathrm{C}, \mathrm{S})=\mathrm{t}($ Venice Centre, Treviso airport $)=1 \mathrm{~h} 14 \mathrm{~min}$.

For Bergamo airport (as for Brescia) we considered the average value of $\mathrm{T}$ estimated over the two principal airports of Milan, Linate and Malpensa.

The analysis of traffic and accessibility data shows four cluster of secondary and regional airports (Figure7). The first cluster is formed by Bergamo, Ciampino and Treviso and has a high score in terms of passenger traffic growth and accessibility. This group of airports follows the same pattern of development, clearly due to the increasing traffic of LCCs and to the proximity of big cities and big hubs. The high degree of accessibility has allowed a huge transfer of passenger traffic from the main hub to the secondary airport, favouring surely "cluster development". In fact, Ciampino is nearer to Rome than Fiumicino (the primary airport of Rome) and both Bergamo and Treviso are easily accessible.

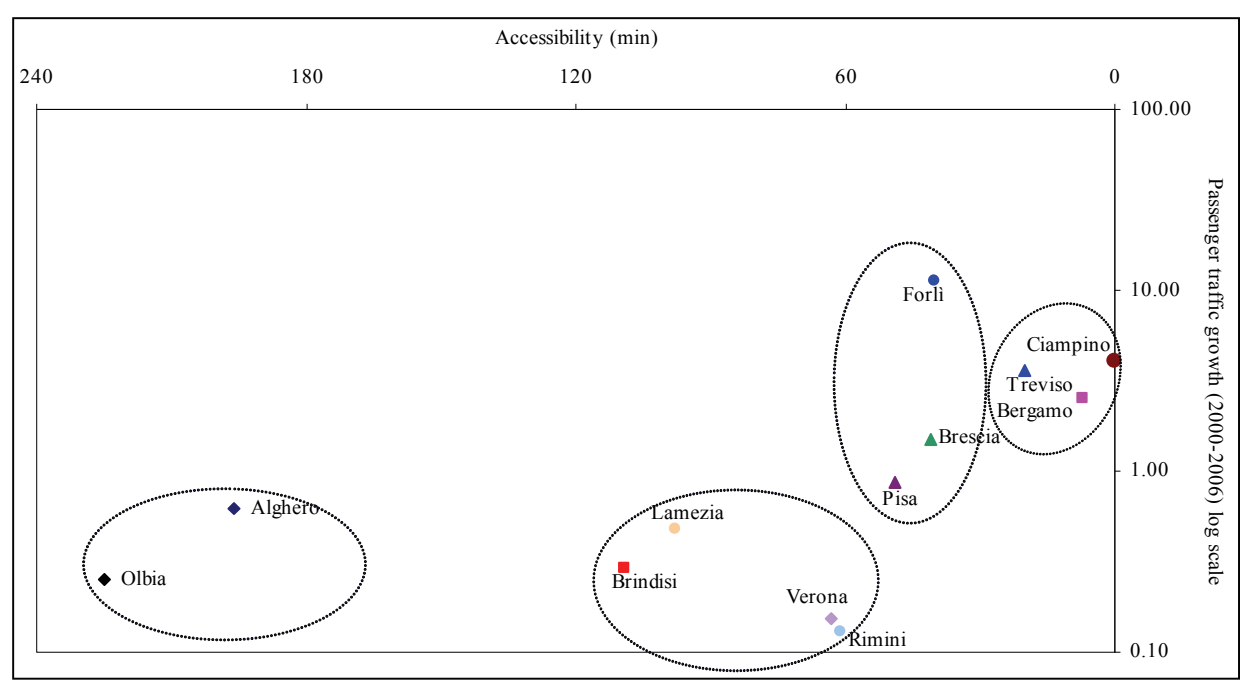

Figure 7. Accessibility and traffic growth. 
Considering a lesser accessibility (20-50 min) and traffic growth, we can make up a second cluster that includes Pisa, Brescia and Forlì: for this group the regional economic development could directly benefit from increasing passenger throughput at secondary airports in terms of "cluster development". In fact, even if the growth of the airport of Pisa and Brescia, regional airports in competition with the airports of Florence and Milan is less remarkable than the airports of the first group, it is noteworthy, in particular for Brescia if we consider cargo traffic. The huge growth of Forlì is explained by its past excessive underutilization (Table 4 and Table 6).

Another pattern of development characterizes Brindisi, Lamezia, Rimini, Verona (third cluster) and Olbia, Alghero (fourth cluster) that show a low growth both of airplane and passenger traffic: in this case development is due to domestic or leisure traffic and the absence of a near main hub has prevented effects of substitution in passenger traffic. Actually, for this group the regional economic development could directly affect occupation and be a catalyst for other on-site economic activities, but the absence of a near industrial environment will certainly not favour a "cluster development".

\section{Conclusions}

Liberalization in Europe has opened up remarkable opportunities for the LCCs. Actually, passengers have benefited from the growth of the LCCs in terms of more competition, more destinations and a greater diversity of fares. If they maintain the $20 \%$ yearly growth that has been seen in the last decade, they will occupy around one third of the European market in a few years time.

Despite the success of the LCCs, however, there is not adequate evidence to conclude that they severely cannibalize the market of the full service carriers, as the great part of the LCC passengers, especially on the shorter routes, are newly generated traffic. Besides, on some major and congested European routes traffic is diverted from the network carriers to LCCs. However, it appears unlikely that the LCCs will enter long-haul markets to any significant extent, as the characteristics of these markets are strongly against the LCC business model. Simplicity and efficiency have been the keys to the success of the LCCs, but for how much more time is the LCC model going to be sustainable? Their continuous expansion expose them to direct competition at the secondary airports, while the traditional full cost carriers are responding more effectively to the LCC business model with lower fares. In fact, the full cost carriers are competing with LCCs on certain point-to-point routes, but they are responding by reducing aircraft size rather than by withdrawing from these routes.

Aviation policy makers are facing several issues connected with the growth of LCCs. Among them there is the necessity to mitigate the environmental effects of this expansion, especially at secondary airports, since a great part of LCCs tend to select routes between regional airports and, as a consequence, these airports are confronted with a rapidly increasing traffic, that requires large capital expenditure for infrastructure.

In this scenario, it is of the utmost importance to ensure high standards of safety, organizing the secure allocation of the increasingly scarce capacity of congested European airports.

The positive aspect of decentralization from main routes is the economic regional development. In fact, regional and secondary airports impact on local economies directly as a catalyst for other on-site economic activities and indirectly as a regional economic multiplier. Moreover, congestion at the major hubs can be lessened by developing secondary hubs: alternative airports around the main urban environment. These are typically remote from the city centre, with plentiful capacity but little traditional scheduled air service. Advantages in terms of lack of congestion and consequently of pollution are set against disadvantages in terms of surface access. While we can conclude that the growth of secondary airports will benefit the surrounding regions, we would need to make a more thorough analysis before being able to even try to quantify the effect of the airport growth on these regions. An interesting line of inquiry would be whether the economic development effects of LCC services differ in different economic settings. It would be interesting to compare the growth of secondary airports and the consequences for regional economic development between Italian regions, in order to understand how introducing LCC services to previously underserved airports affects the surrounding regions.

\section{References}

[1] R. Windle and D. Martin, "Competitive Responses to Low Cost Carrier Entry," Transportation Research Part E, Vol. 35, No. 1, 1999, pp. 59-75.

[2] C. A. Scheraga, "Operational Efficiency Versus Financial Mobility in the Global Airline Industry: A Data Envelopment and Tobit Analysis," Transportation research Part A, Vol. 38, No. 5, 2004, pp. 383-404.

[3] K. J. Button, "Wings across Europe: Towards an Efficient European Air Transport System," Aldershot, Ashgate, 2004.

[4] K. J. Button, "Air Transport: Airports and Regional Economic Development," In: M. Lupi Ed., Methods and Models for Planning the Development of Regional Airport Systems, FrancoAngeli, Milan, 2008, pp. 9-28.

[5] N. Carbonara, "Innovation Processes within Geographical Clusters: A Cognitive Approach," Technovation, Vol. 24, No. 1, 2004, pp. 17-28.

[6] J. Bain, "Barriers to New Competition", Harvard University Press, Cambridge, 1956. 
[7] Eurocontroll, "STATFOR Documents," 2006. http://www. eurocontrol.int/

[8] International Air Transport Association (IATA), "Analysis and Reports from IATA Economics," 2006. http:// www. iata.org/

[9] International Civil Aviation Organization (ICAO), "ICAO Journal," 2006. http://www.icao.int/

[10] P. Morrell, "Airlines within Airlines: An Analysis of US Network Airline Responses to Low Cost Carriers," Journal of Air Transport Management, Vol. 11, No. 5, 2005, pp. 303-312.

[11] K. J. Mason, "The Propensity of Business Travellers to Use Low Cost Airlines," Journal of Transport Geogra- phy, Vol. 8, No. 2, 2000, pp. 107-119.

[12] Association of European Airlines (AEA), "AEA Traffic Report," 2002-2006. http://www.aea.be/

[13] J. F. O'Connell and G. Williams, "Passengers' Perceptions of Low Cost Airlines and Full Service Carriers: A Case Study Involving Ryanair, Aer Lingus, Air Asia and Malaysia Airlines," Journal of Air Transport Management, Vol. 11, No. 4, 2005. pp. 259-272.

[14] P. Horder, “Airline Operating Costs," Presented at Managing Aircraft Maintenance Costs Conference, Brussels, 2003.

[15] Assaeroporti, “Airports Database,” 2000-2006. http:// www.assaeroporti.it/ 